- Outlines the features that a group of general dental practitioners look for in a dental implantology course.

- Provides insight into the motivations of these general dental practitioners in deciding whether they wish to provide dental implant treatment.

- Highlights the views held by these general dental practitioners on dental implant education.

\title{
Dental implantology education: a survey of opinion and experience of 106 general dental practitioners
}

\author{
R. L. Gibson ${ }^{1}$ and C. W. Barclay ${ }^{2}$
}

\begin{abstract}
In the United Kingdom the National Health Service only provides dental implant treatment to patients who fulfil stringent clinical criteria outlined by the Royal College of Surgeons. Such treatment is normally in a hospital setting. The majority of dental implant work is otherwise carried out in the private sector. Concern about the quality of implant dentistry and training led the General Dental Council to convene a working group that set out to set training standards in implant dentistry for general dental practitioners (GDPs). The Faculty of General Dental Practitioners published this guidance in March 2006. This questionnaire based study set out to examine GDP attitudes to implant treatment and training and aims to contribute to the debate and review of appropriate training in dental implantology for GDPs .
\end{abstract}

\section{INTRODUCTION}

The use of dental implants in the treatment of the edentulous jaw has proved effective in the long term. ${ }^{1}$ More recently, the efficacy of dental implants in the treatment of the partially dentate patient has also been demonstrated..$^{2,3}$ Mainly, specialist institutions have conducted this research.

Dental implant sales continue to rise $^{4-6}$ and as public awareness and demand increases, many more GDPs will inevitably want to provide dental implant treatment. Research exists ${ }^{7-9}$ which demonstrates the efficacy of dental implant treatment when provided by GDPs, but such research has only been conducted over the short term.

Meanwhile, there has been a proliferation in the number of courses offered and targeted at GDPs, ranging from one day courses to degree level qualifications.

\footnotetext{
1*Honorary Clinical Assistant, University Dental Hospital of Manchester, Higher Cambridge Street, Manchester, M 15 6FH; ${ }^{2}$ Consultant in Restorative Dentistry, University Dental Hospital of Manchester, Higher Cambridge Street, Manchester, M15 6FH *Correspondence to: Dr Robin Gibson Email: r.l.gibson@lycos.co.uk
}

\section{Refereed Paper}

Accepted 15 February 2006

DOI: $10.1038 /$ sj.bdj.4814043

$\odot$ British Dental Journal 2006; 201: 367-370
Surveys of the availability and composition of courses in oral implantology provided by dental schools of the UK and Eire have been published in $1993^{10}$ and 1999. ${ }^{11}$ However, there has been no published assessment of private institution provision. Moreover, a survey of members of the Association of Dental Implantology (ADI) between July 1998 and May 1999, found that more than a third of its members contributed to implantology teaching in private institutions. ${ }^{12}$ Therefore, research into the requirements of GDPs in relation to dental implant education and the quality and quantity of such opportunities would be beneficial.

No dental implant education surveys specifically of GDPs could be found that have been published in the UK. Internationally, there has been some research and comment related to dental implant education and GDPs. ${ }^{13-17}$ This paper aims to contribute to the discussion/debate on the appropriate training for GDPs through a survey of opinion and experience of GDPs who attend a local continuing professional development event.

\section{METHODS}

GDPs attending a continuing professional development course were the chosen population for this cross sectional questionnaire survey. The course is held one evening every fortnight over the academic year and is intended for GDPs working mainly in the middle and southern areas of the Northwest of England. The survey period was spread over four consecutive course evenings during March and April of 2004. A minimum sample size of 100 was thought to be achievable in the time available for the survey.

\section{The questionnaire}

A seven page questionnaire was used to gather information about respondent's background, experience and attitudes of relevance to dental implant education. Respondents were required only to complete a maximum of five different pages as directed by the questionnaire.

The questions used were broadly grouped into three parts:

i) Practitioner profiling questions

ii) Questions concerning general attitudes to dental implant treatment

iii) Specific questions depending on whether the respondent - was already providing dental implant treatment - would like to provide dental implant treatment

- did not want to provide dental implant treatment. 
Table 1 Dental implant experience and aspirations

\begin{tabular}{l|l|l|l}
\hline & Yes & No & Missing \\
\hline Dental implant experience & $3(2.8 \%)$ & $103(97.2 \%)$ & 0 \\
\hline Desire to provide in future & $37\left(35.9 \% \%^{*}\right)$ & $64\left(62.1 \% \%^{*}\right)$ & $2\left(2.0 \% \%^{*}\right)$ \\
\hline *Percentage of the 103 who had no dental implant experience.
\end{tabular}

Table 2 Course feature preferences

\begin{tabular}{l|l|l}
\hline & Number & Percentage* \\
\hline Lectures & 23 & 63.9 \\
\hline Small group seminars/tutorials & 30 & 83.3 \\
\hline Case reports & 20 & 55.6 \\
\hline Simulated practicals on lab bench & 12 & 33.3 \\
\hline Simulated practicals on a phantom head & 25 & 69.4 \\
\hline Live demo's on patients & 27 & 75.0 \\
\hline Supervised treatment on patients & 29 & 80.6 \\
\hline Post-course support & 29 & 80.6 \\
\hline *The percentage is of the whole group of 36 practitioners for each feature. &
\end{tabular}

A null hypothesis proposed that there was no difference between the three practitioner groups, stated in part iii), in their responses to relevant questions in parts i) and ii).

A pilot survey of five general dental practitioners not connected with the AURC event was conducted prior to the survey to help refine the questionnaire.

Questionnaires were distributed at each event with care being taken not to provide one to those who had previously responded.

\section{Method of analysis}

All questionnaires had their date of completion entered at each sample collection. Questionnaires were then counted and sorted into four groups. Any questionnaires that had been completed by clinicians who were not GDPs were excluded from the survey. The first group of questionnaires related to those who presently provided dental implant treatment, the second to those who did not but wished to and the third to those who did not provide and did not wish to provide dental implant treatment. The fourth group consisted of incomplete questionnaires that could not be placed in any of the first three groups.

Data from the questionnaires were categorised and entered into the SPSS computer programme. The data included the date of completion and the respondent's name or GDC number to ensure, where possible, that respondents had not accidentally completed two questionnaires. Where respondents had not entered a response(s) for a particular question, or the response entered was not appropriate, then a missing data entry was made.

After all the raw data were compiled, they were analysed in respect of the number of responses or kinds of response as appropriate. Chi square analysis was used to detect differences between the first three groups mentioned above in their response to relevant questions.

\section{RESULTS}

The total number of questionnaires included in the study was 106. Outright refusal to complete a questionnaire was experienced from a potential respondent on one occasion. Of the 106 questionnaires collected, five were either partially or poorly

Twenty-one (19.8\%) respondents had had a postgraduate qualification, of which 15 had a membership/diploma to one of the Faculties of the Royal Colleges of Surgeons. Three had a postgraduate degree while four had another form of postgraduate qualification. Five (4.7\%) respondents stated they were presently studying for a further dental qualification.

Twenty-six (24.5\%) respondents had teaching in implantology as an undergraduate. Fifteen (14.2\%) said that they had colleagues in their practice that provided implant treatment.

\section{General opinion related to dental implantology}

Seventy-three (68.9\%) thought that there was a market for dental implants amongst their patients. Several reasons for this response were given including increasing patient awareness and requests, increased clinical options, increasing number of referrals and that their practice was already providing implant treatment. The fact there was no local competition was given by one practitioner.

Seventy-one (63.0\%) respondents thought that the medico-legal risks completed. associated with dental implant treatment were high; the rest thought they were medium (28.3\%) or low (1.9\%). When asked if they thought a dentist should have an implantology qualification that could be registered with the GDC before advertising that they provide dental implant treatment, 73 (68.9\%) said yes, 15 (14.2\%) said no and $18(17 \%)$ had no opinion. Seventy-four (69.8\%) respondents thought that there should be a specialist list in implantology while $11(10.4 \%)$ thought there should not be. Twenty-one (19.8\%) had no opinion.

Seventy-eight (73.6\%) respondents believed that dental implant treatment should be carried out, but not necessarily exclusively, by consultants or specialists in hospitals. Eighty-five (80.2\%) believed that dental implant treatment should be carried out, but not necessarily exclusively, by specialists in practice. Thirty-three $(31.1 \%)$ said GDPs could carry out dental implant treatment in practice. Seventyseven $(72.6 \%)$ believed specialists and GDPs working together could provide dental implant treatment.

Nearly all (88.7\%) respondents believed the use of dental implant treatment in the UK would generally increase and that GDPs have a role to play in educating patients about the benefits of implants (90.6\%). One hundred and four (98.1\%) respondents believed GDPs have a role to play in stating the option of implants to patients where appropriate, but only $66.0 \%$ of respondents believed GDPs have a role to play in the maintenance of implants.

\section{Implant experience/aspirations}

Only three $(2.8 \%)$ respondents had placed or restored dental implants in their own dental practices. Of the 103 who had no experience, 37 (35.9\%) wanted to provide implant treatment in the future. These results are summarised in Table 1.

\section{Differences in answers between practitioner groups}

The number of respondents who had provided dental implant treatment was too small to be subjected to statistical tests. Differences between those who did or did not want to provide dental implant treatment were tested with respect to their answers to relevant questions in the first section of the questionnaire. No statistically significant differences were found in any of the comparisons except those now described.

A significantly higher proportion of those who wanted to provide implants were studying for a further qualification compared with those who did not want to provide implants $(p=0.003)$. Furthermore, a significantly higher proportion of those who wanted to provide implants thought dental implant treatment in the UK would 
increase compared with those who did not want to provide ( $p=0.028)$. Lastly, a significantly higher proportion of those who wanted to provide implants thought they had a role to play in the maintenance of implants compared with those who did not want to provide ( $p=0.039$ ).

\section{Practitioners who had provided dental implant treatment}

All three respondents who had provided dental implant treatment in their practices had only provided the restorative phase. Of these three practitioners, one had previously attended a course run by a dental school/university with sponsorship from a dental implant company. Two practitioners had previously attended private practice/institution-run dental implant courses that had no commercial bias. Of these two clinicians, one had also attended a private practice/institution run dental implant course that was sponsored by a dental implant company. The other clinician had also attended another course which had been run by a dental school/university and had no commercial bias.

When asked about their future plans regarding implant training all three wanted to increase the number of patients that they treated with dental implants. One wanted to continue with the type of implant treatment they had been doing, one wanted to do more complex cases and the other wanted to add other implant systems to their practice.

When asked about how they would update or attain new knowledge about dental implantology, all three thought it appropriate to read books, journals and the dental press, attend lectures and go on advanced courses. Two also thought observing more experienced colleagues or mentors was appropriate.

None of the three practitioners were members of a dental implant society. Additionally, all three of these practitioners thought the standard of implant courses was generally good.

\section{Those who want to provide treatment}

Of the 37 who wanted to provide dental implant treatment, one failed to complete the questionnaire. Of the 36 remaining, 21 (58.3\%) were merely 'thinking about it', seven (19.4\%) were actively looking for an appropriate course while a further three $(8.3 \%)$ were not looking for a course but stated that they would self-teach using available texts and media. Three (8.3\%) practitioners had finished an implant course but not yet provided any treatment, a further practitioner (2.8\%) was presently attending an implant course while another one $(2.8 \%)$ was booked on but had not yet started an implant course.
Twenty-nine respondents (80.6\%) wanted to provide both the surgical and restorative phases of dental implant treatment. The rest of the respondents (seven or $19.4 \%$ ) wanted only to provide the restorative phases. None therefore wished to provide the surgical phase alone.

The respondents were asked which feature(s) they would look for when choosing an implant course. The results are summarised in Table 2.

In addition, the respondents were asked what they expected or believed a dental implant course would allow them to do once they had completed it. The results are summarised in Table 3.

Ten (27.8\%) respondents knew of a dental implant course that fulfilled their requirements and of those, nine (90\%) considered that the course was within a reasonable distance of their practice. Twentyfive (69.4\%) respondents did not know of any courses that fulfilled their needs. There was one missing response for this question. When asked what they believed the standard of implant courses to be, 19 (52.8\%) had no opinion, eight $(22.2 \%)$ thought them variable, six (16.7\%) thought they were generally good, while $2(5.6 \%)$ thought they were generally poor and one $(2.8 \%)$ thought they were generally adequate.

When asked if the financial implications of undertaking an implant course may affect their decision as to the type of course they would undertake, 23 (63.9\%) said yes.

Table 3 Expectations of post-course abilities

\begin{tabular}{l|l|l}
\hline & Number & Percentage* $^{*}$ \\
\hline Simple surgical cases & 25 & 69.4 \\
\hline Moderate surgical cases & 8 & 22.2 \\
\hline Complex surgical cases & 0 & 0 \\
\hline Simple restorative cases & 29 & 80.6 \\
\hline Moderate restorative cases & 20 & 55.6 \\
\hline Complex restorative cases & 1 & 2.8 \\
\hline *The percentage is of the whole group of 36 practitioners for case type. & &
\end{tabular}

Table 4 Factors preventing practitioners providing dental implants in the future

\begin{tabular}{|l|l|l|}
\hline & Number & Percentage \\
\hline No interest & 10 & 15.6 \\
\hline Too complex & 19 & 29.7 \\
\hline Higher medico-legal risk & 45 & 70.3 \\
\hline Cost of equipment and training & 46 & 71.9 \\
\hline No market for implants in my practice & 26 & 40.6 \\
\hline Too busy with other treatments/ practice management & 29 & 45.3 \\
\hline No support within practice & 10 & 15.6 \\
\hline Other & 9 & 14.1 \\
\hline *The percentage is of the whole group of 64 practitioners for each factor. & &
\end{tabular}

\section{Those who do not want to provide implant treatment}

Respondents were asked what prevented them from wanting to provide implant treatment in the future. The results (Table 4) show that the most important factors

Since graduating from dental school 55 $(84.4 \%)$ indicated they had attended single lecture(s) regarding dental implants. Eight (12.5\%) indicated they have attended didactic course(s) with no practical element while five $(7.8 \%)$ indicated they have attended didactic course(s) with a practical element. Nine (14.1\%) indicated they had not attended any lecture or course since graduating, seven of which had been practising for four or more years (two for more than 20).

When asked how confident they were in assessing if dental implants were not appropriate for a given patient, 37 (57.8\%) indicated they were reasonably confident, dence, two (3.1\%) felt very confident while one $(1.6 \%)$ had no confidence.

\section{DISCUSSION}

The population chosen for this questionnaire survey may not be representative of all general dental practitioners as they are a group who are committed to further postgraduate education. However, this survey does give insight into the opinions of a relevant group of GDPs who attend a continuing professional development event. were risks and costs. $24(37.5 \%)$ indicated they had little confi- 
Very few GDPs in the survey provided implant treatment. Those who did generally wanted to increase the amount and, in some cases, the complexity of the treatment they provided and thought they would achieve this aim by increasing their knowledge. Methods by which more knowledge could be gained were through reading and by attending lectures and advanced courses, including clinical observation. They all reported the standard of courses to be generally good. The limited numbers providing treatment may reflect the relatively new spread of implant dentistry into general dental practice, and may also reflect a lack of appropriate training and hesitance to get involved in what seems a complex discipline. Additionally the same reasons may explain why only a minority of the GDPs surveyed (approximately one third) wanted to get involved in implant dentistry. Even then, further examination of the data revealed only a small proportion were actually active in searching for courses, suggesting many in this group may never take up training. However, as one sixth of the GDPs surveyed had colleagues who provided dental implant treatment, the sample may have had a lower proportion of GDPs who provide implant dentistry than is present in the GDP population at large.

Of those who wished to provide implant treatment, the majority wanted to provide both simple surgical and restorative aspects which may reflect the desire of GDPs to provide all aspects of treatment for their patients. GDPs in this group also seem to want a reasonably priced course that provided close teaching and supervised treatment with support after completion of training. This combination of preferences may reflect a cautious approach when engaging in implant dentistry. However, it was worrying that the small number of GDPs who wished to provide dental implant treatment thought it appropriate to teach themselves using text and media resources.

The majority of GDPs had not been taught oral implantology as an undergraduate, an indication of the relative immaturity of this field. However, it was a welcome finding that most had been on an implant educational course/lecture since graduating, because it is essential that GDPs are able to offer their patients adequate information and opinion about dental implants. It is of concern, however, that nine GDPs had not been on a course since graduating, seven of which had been qualified for four or more years! Although it may be possible to gain a reasonable knowledge of dental implantology from texts and media, it would seem unlikely that all these practitioners are doing so diligently. When considered with the fact that more than a third had little or no con- fidence as to whether implant treatment was inappropriate in any given case, the possibility arises that inappropriate referrals will be made or, worse still, dental implants are not considered where they may be a legitimate option. Therefore, it is potentially urgent that some GDPs equip themselves with at least a minimum knowledge of dental implantology.

Only a minority of GDPs thought they had a role to play in the maintenance of implants. Moreover, those practitioners who wanted to provide dental implant treatment were more likely to believe they had a maintenance role than those that did not. This result is worrying. As the number of patients with implants increases, more GDPs will be faced with having to deal with implant monitoring and maintenance issues. Referral options certainly within the NHS are uncertain and pressure from patients for local provision of dental treatment may increase. If large numbers of GDPs do not gain the necessary knowledge to provide implant maintenance then problems may occur. Clarification by the GDC of a GDP's responsibilities with regard to implant monitoring and maintenance may now be appropriate. Fortunately, a vast majority of the GDPs surveyed thought that they, at least, have a role in educating patients about dental implants and in suggesting the option of implants to patients where appropriate. This finding reflects an understanding of professional responsibility to specific patients and the dental health of the community in general.

The vast majority of GDPs surveyed thought the use of dental implant treatment in the UK would increase, which may reflect their increasing awareness of implantology. A further interesting finding was the association between the wish to provide implant treatment in the future and the desire to seek further qualifications. This finding may be of interest to implant companies and education providers because these GDPs may be a more lucrative market.

The majority of GDPs surveyed thought the medico-legal risks of dental implantology were high. The higher medico-legal risk and the cost of equipment and training associated with dental implant treatment seemed to be a prime factor in deterring those GDPs who did not want to provide dental implant treatment. Both these findings suggest that these GDPs generally consider that dental implant treatment is a difficult treatment mode to provide successfully. The perception of difficulty may also be reflected in the finding that only one third of GDPs surveyed thought that GDPs should carry out dental implant treatment alone in practice and that the majority of GDPs believed qualifications were necessary before adver- tising their implant skills. Furthermore, the majority of GDPs thought there should be a speciality in dental implantology. Greater than two thirds also believed an appropriate approach for GDPs was to work with specialists in providing dental implant treatment. Therefore, it seems that the majority of GDPs agree on the place of implants in general dental practice.

A further survey of a broader population of GDPs would be advantageous and may contribute to dental implant education, practice and regulation.

\section{CONCLUSION}

There was majority agreement between general dental practitioners in the questionnaire about many aspects of dental implant education, practice and regulation.

The authors wish to thank Ann-Marie Glenny for her help in the design of the questionnaire.

1. Adell R, Lekholm U, Rockler B, Branemark P. 15 year study of osseointegrated implants in the treatment of the edentulous jaw. Int J Oral Surg 1981; 10: 387-416.

2. Zarb G A, Schmitt A. The longitudinal clinical effectiveness of osseointegrated dental implants in posterior partially edentulous patients. Int J Prosthodont 1993; 6: 189-196.

3. Creugers N H, Kreulen C M, Snoek P A, de Kanter R $J$. A systematic review of single-tooth restorations supported by implants. J Dent 2000; 28: 209-217.

4. US Markets for Dental Implants. Executive Summary. Implant Dent 2003; 12: 108-111.

5. Japanese Markets for Dental Implants. Annual Industry Report. Implant Dent 2003; 12: 272-274.

6. European Markets for Dental Implants. Annual Industry Report. Implant Dent 2003: 12: 268-271.

7. Sethi A, Harding S, Sochor P. Initial results of the Osteo Ti implant system in general dental practice. Europ J Prosthod Rest Dent 1996; 4: 21-28.

8. Andersson $B, O d$ man $P$, Lindvall A M, Branemark $P$ I. Surgical and prosthodontic training of general practitioners for single tooth implants: a study of treatments performed at four general practitioners offices and at a specialist clinic after 2 years. J Oral Rehabilitation 1995; 22: 543-548.

9. Henry PJ, Rosenberg I R, Bills I G et al. Osseointegrated implants for single tooth replacement in general practice: a 1-year report from a multicentre prospective study. Aust Dent J 1995; 40: 173-181.

10. Watson R M. The teaching of osseointegrated implant dentistry in the schools of the UK and Eire. BrDent J 1993; 175: 201-203.

11. Young M P, Carter D H, Sloan P, Quayle A A. A survey of oral implantology teaching in the university dental hospitals and schools of the United Kingdom and Eire. Br Dent J 1999; 187: 671-675

12. Young M P, Carter D H, Sloan P, Quayle A A. Survey of clinical members of the association of dental implantology in the United Kingdom: Part I. Levels of activity and experience in oral implantology. Implant Dent 2001; 10: 68-74.

13. Klugman $R$, Sgan-Cohen $H$, Stern N. A survey of dentists practicing implant dentistry in Israel. J Prosthet Dent 1990; 64: 473-478.

14. Brandt R L, Fitzpatrick B J, Moloney F B, Bartold P $M$. Continuing dental education in osseointegrated implants. A survey. Aust Dent J 2000; 45: 285-288.

15. Payant L et al. Survey of Dental Implant Practice. J Oral Implantol 1994; 20: 50-58.

16. Christensen G J. Clinical Research Associates, Provo, Utah 84604, USA. Implants and general practitioners. J Amer Dent Assoc 2000; 131: 359-361.

17. Caplanis N, Kan J Y, Lozada J L. Implant dentistry education for the practicing dentist. J CalifDent Assoc 2001; 29: 757-764. 